Further experience in essential hypertension with low doses of captopril will be required to determine whether converting enzyme inhibition can be extended to the much larger group of mild to moderate hypertensive patients.

\section{Captopril in congestive cardiac failure}

Captopril can produce considerable short term haemodynamic improvement in patients with refractory heart failure, and there is evidence of long term symptomatic relief. Its beneficial effects appear to result from actions on both arterial and venous sides of the circulation. As with other recent developments in managing heart failure by reduction of preload or afterload, or both, captopril should at present be reserved for patients with persistent symptoms and signs not responding to conventional treatment with diuretics or digoxin or both. Patients taking diuretics should start with a low dose of captopril, which may then be increased under close supervision.

\section{Conclusion}

Since most patients with hypertension can be adequately controlled by once daily treatment with a beta-blocker or a thiazide diuretic and with few adverse reactions the drugs described above will have limited appeal for first line treatment at present. Prazosin and captopril have a place in treating the more resistant forms of hypertension and prazosin might also be used in low doses, combined with a diuretic, for those patients who are unable to take a beta-blocker. Labetalol has the disadvantage of its dosing frequency while indoramin has the disadvantage of its unwanted effects.

Both prazosin and captopril may improve symptoms in patients with refractory congestive cardiac failure. There is no evidence, however, that these agents alter the clinical course of the disease. For the present their use should be restricted to those patients who remain symptomatic despite conventional treatment with diuretics or digitalis preparations, or both.

\section{Bibliography}

Atkinson AB, Robertson JIS. Captopril in the treatment of clinical hypertension and cardiac failure. Lancet 1979;ii:836-9.

Review of clinical experience of captopril in severe, resistant hypertension and renal artery stenosis indicating that the drug is of similar efficacy to triple treatment. Also includes assessment of captopril in heart failure.

Sharpe DN, Coxon RJ, Douglas JE, Long B. Low dose captopril in chronic heart failure: acute haemodynamic effects and long term treatment. Lancet 1980;ii:1154-7.

Study of low dose captopril in 18 patients with heart failure showing beneficial effects.

Campbell BC, Shepherd AN, Reid JL. Effects of the angiotensin converting enzyme inhibitor captopril in essential hypertension. Brf Clin Pharmacol $1972 ; 13: 213-7$.

Patients who were not controlled on $150 \mathrm{mg}$ a day were not controlled on higher doses without the addition of a diuretic.

Rubin PC, Braschke TF. Clinical pharmacology of prazosin. $\mathrm{Br} \mathcal{f}$ Clin Pharmacol 1980;10:23-32.

An account of the clinical pharmacology of prazosin together with a detailed review of earlier papers. Documents reflex tachycardia and increased plasma renin concentration.

Anonymous. Labetalol for hypertension. Drug Ther Bull 1978;16:89-90.

An objective assessment of the clinical pharmacology and clinical use of labetalol.

Anonymous. Indoramin for hypertension. Drug Ther Bull 1982;20:33-5. An objective assessment of current publications.

Robertson JIS. Labetalol: the nineteen-eighties. Br $\mathcal{f}$ Pharmacol 1982;13, suppl $1: 137 \mathrm{~S}-141 \mathrm{~S}$.

A summary of the clinical experience, including essential hypertension, phaeochromocytoma, ischaemic heart disease, and pregnancy based on conference proceedings.

Indoramin. Br 7 Clin Pharmacol $1981 ; 12$,suppl 1.

Conference proceedings containing an up to date review of clinical use with a summary (Turner P, 139s-140s) and a general discussion (Hamer $\mathrm{J}, 23 \mathrm{~s}-26 \mathrm{~s}$ ) of the use of vasodilators in treating congestive heart failure.

\title{
New Devices
}

\section{Drug convertarule}

\author{
M J BRODIE, A ROBSON, T MURRAY
}

\begin{abstract}
A convenient pocket ruler has been developed that allows conversion between metric and molar measurements of many of the drugs for which therapeutic monitoring in the circulation is commonly used. The ruler also gives information to the clinician on suggested therapeutic ranges for the incorporated drugs.
\end{abstract}

\footnotetext{
Departments of Medicine, Medical Illustration, and Pharmacy, Western Infirmary, Glasgow G11 6NT

M J BRODIE, MD, MRCP, consultant physician and clinical pharmacologist A ROBSON, DA, medical artist

T MURRAY, BSC, MSC, principal radiopharmacist

Correspondence to: Dr M J Brodie, Department of Medicine, Gardiner Institute, Western Infirmary, Glasgow G11 6NT.
}

\section{Introduction}

The fine tuning of plasma drug concentration to optimise pharmacological response and avoid toxicity is an attractive concept that is finding increasing favour with clinicians. In most hospitals departments of biochemistry provide estimations of drug concentrations. Clinical pharmacists and clinical pharmacologists may help to interpret the figures and provide advice on adjustment of the dosage to help attain a therapeutic concentration. Drug concentrations are increasingly being provided in the molar units favoured by scientists, despite the fact that drugs are still prescribed in metric amounts. Several conversion scales have been produced. 1 To avoid possible errors of interpretation, we have developed a convenient pocket ruler that not only converts molar units to metric units but also provides information on the therapeutic ranges of several drugs for which routine plasma monitoring is commonly used. 
Drug convertarule (figs 1-4)

For each drug on the convertarule there is a dual row of figures with metric units above and molar units below. The box through which the figures are visualised shows the recommended therapeutic ranges for the drugs when the rule is in the "resting" position with only the handling tab visible on each side. A colour code has been used for those drugs for which there is good clinical evidence to support a therapeutic range. The codes are yellow for low concentrations, blue for
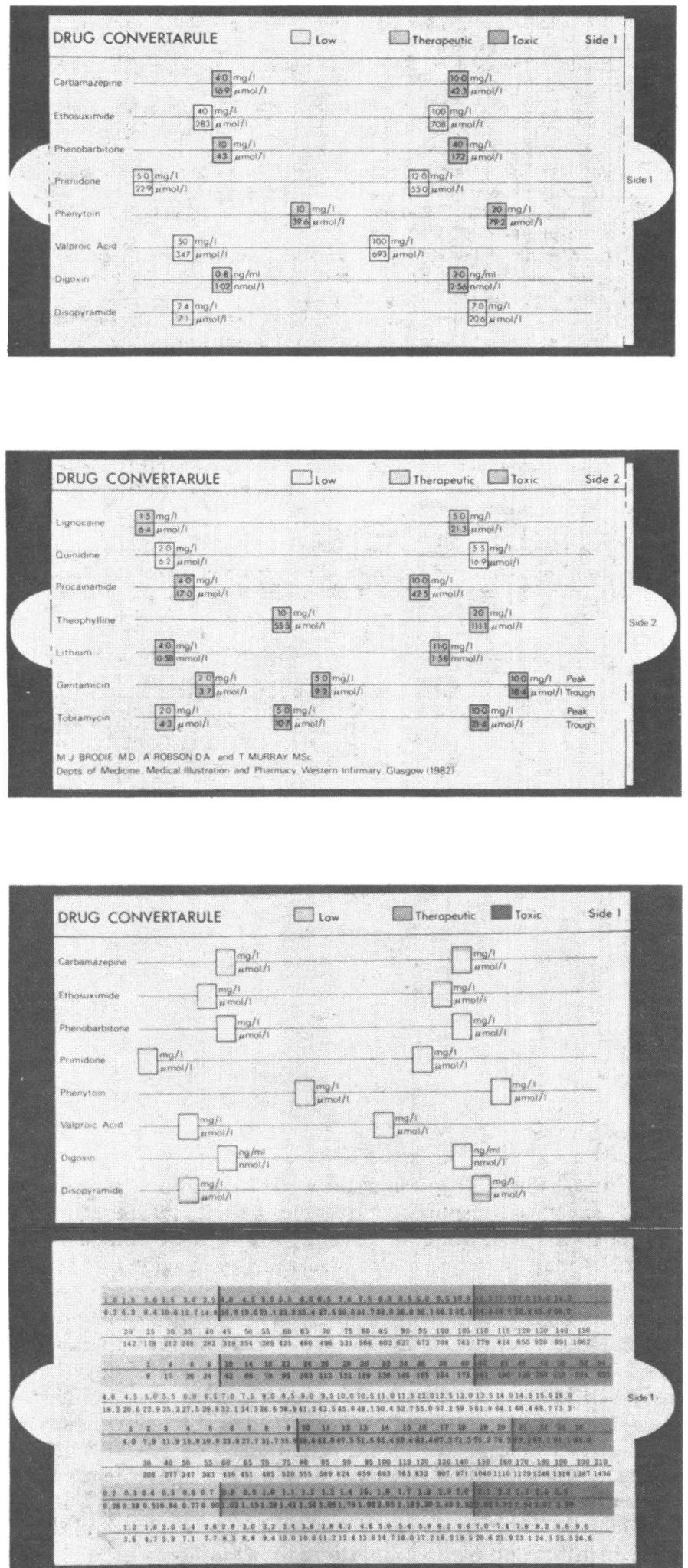

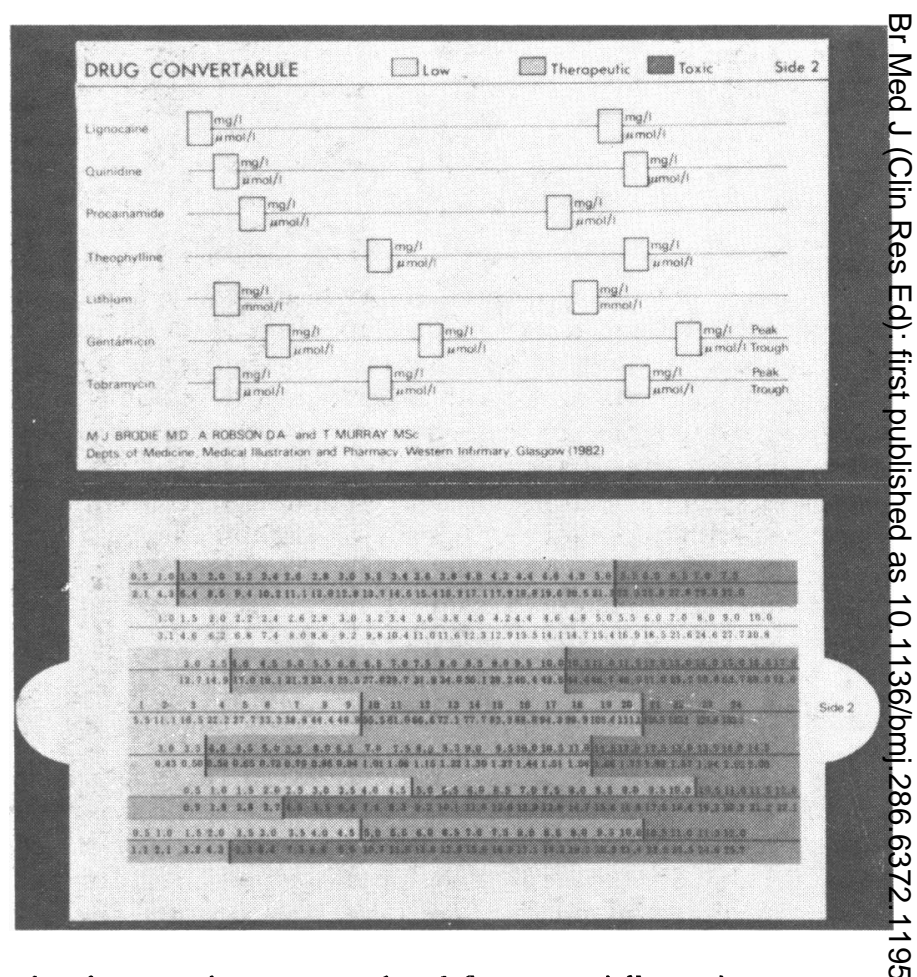

the therapeutic range, and red for potentially toxic concentra tions. For the aminoglycosides, gentamicin and tobramycin, the colour coding for the peak and trough concentrations are in the metric and molar columns respectively. The rows have been? left uncoloured for those drugs for which a therapeutic range has been suggested but remains to be confirmed. All the value $5_{0}^{\circ}$ have been taken from the reviews included in a recently pubê lished textbook Therapeutic Drug Monitoring. ${ }^{2}$ The table list: the ranges of figures incorporated in the convertarule.

Suggested therapeutic ranges incorporated into the drug convertarule

\begin{tabular}{|c|c|c|}
\hline Drug & Metric units & Molar units \\
\hline Carbamazepine & $4-10 \mathrm{mg} / \mathrm{l}$ & $17-42 \mu \mathrm{mol} / 1$ \\
\hline Ethosuximide* & $40-100 \mathrm{mg} / \mathrm{l}$ & $283-708 \mu \mathrm{mol} / 1$ \\
\hline Phenobarbitone & $10-40 \mathrm{mg} / \mathrm{l}$ & 43-172 $\mu \mathrm{mol} / 1$ \\
\hline Primidone* & $5-12 \mathrm{mg} / 1$ & $23-55 \mu \mathrm{mol} / 1$ \\
\hline Phenytoin & $10-20 \mathrm{mg} / 1$ & $40-80 \mu \mathrm{mol} / 1$ \\
\hline Valproic acid* & $50-100 \mathrm{mg} / \mathrm{l}$ & $347-693 \mu \mathrm{mol} / 1$ \\
\hline Digoxin & $0 \cdot 8-2 \mathrm{ng} / \mathrm{ml}$ & $1-2.6 \mathrm{nmol} / 1$ \\
\hline Disopyramide* & $2 \cdot 4-7 \mathrm{mg} / 1$ & $7.1-20.6 \mu \mathrm{mol} / 1$ \\
\hline Lignocaine & $1.5-5.0 \mathrm{mg} / 1$ & $6.4-21.3 \mu \mathrm{mol} / \mathrm{l}$ \\
\hline Quinidine* & $1.5-5.5 \mathrm{mg} / \mathrm{l}$ & $6 \cdot 2-16.9 \mu \mathrm{mol} / 1$ \\
\hline Procainamide & $4-10 \mathrm{mg} / \mathrm{l}$ & $17-42.5 \mathrm{umol} / \mathrm{I}$ \\
\hline Theophylline & $10-20 \mathrm{mg} / 1$ & $55 \cdot 5-111 \mu \mathrm{mol} / \mathrm{I}$ \\
\hline Lithium & $4-11 \mathrm{mg} / \mathrm{l}$ & $0.6-1.6 \mathrm{mmol} / \mathrm{i}$ \\
\hline Gentamicin: peak & $5-10 \mathrm{mg} / 1$ & $9-18 \mu \mathrm{mol} / \mathrm{l}$ \\
\hline Tobramycin: peak & $5-10 \mathrm{mg} / \mathrm{l}$ & $11-21 \mu \mathrm{mol} / 1$ \\
\hline trough & $\leqslant 2 \mathrm{mg}$ & $\leqslant 4.3 \mu \mathrm{mol} / 1$ \\
\hline
\end{tabular}

* Unconfirmed.

We thank Mrs Carol Downes for expert secretarial help. An application for a patent has been filed.

\section{References}

1 Deom A, Aeschlmann JM, Aellig A. Conversion scales for commonl requested serum concentrations of drugs and other substances oD therapeutic and toxicological importance and of hormones. Lance $1980 ; \mathrm{i}: 1241-4$.

${ }^{2}$ Richens A, Marks V, eds. Therapeutic drug monitoring. Edinburgh Churchill Livingstone, 1981.

(Accepted 27 fanuary 1983) 